УДК 633.522:632.93:631.53.01

https://doi.org/10.32634/0869-8155-2021-348-4-60-63

Краткий обзор/Brief review

Бакулова И.В.,

Плужникова И.И.,

Криушин Н.В.

ФГБНу «Федеральный научный центр лубяных культур», Россия, Пензенская область, р. п. Лунино

E-mail: i.bakulova.pnz@fnclk.ru

Ключевые слова: конопля посевная, безнаркотический сорт, урожайность стеблей и семян, жидкое минеральное удобрение, внекорневая подкормка, обработка семян

Для цитирования: Бакулова И.В., Плужникова И.И., Криушин Н.В. Влияние технологических приемов на продуктивность конопли посевной в условиях лесостепи Среднего Поволжья. Аграрная наука. 2021; 348 (4): 60-63.

https://doi.org/10.32634/0869-8155-2021-348-4-60-63

Конфликт интересов отсутствует

Irina V. Bakulova,

Irina I. Pluzhnikova,

Nikolay V. Kriushin

Federal state budgetary scientific institution

"Federal scientific center of bast crops",

Russia, Penza oblast, r. p. Lunino

Key words: crop hemp, drug-free variety, yield of stems and seeds, liquid mineral fertilizer, foliar top dressing, seed treatment

For citation: Bakulova I.V., Pluzhnikova I.I., Kriushin N.V. Influence of technological techniques on the productivity of hemp in the conditions of the forest-steppe of the Middle Volga region. Agrarian Science. 2021; 348

(4): 60-63. (In Russ.)

https://doi.org/10.32634/0869-8155-2021-348-4-60-63

There is no conflict of interests

\section{Влияние технологических}

приемов на продуктивность

конопли посевной в условиях лесостепи Среднего Поволжья

\section{PEЗЮME}

Представлены результаты научно-исследовательской работы 2017-2020 годов по влиянию предпосевной обработки семян и некорневой подкормки растений на увеличение урожайности и качества продукции конопли посевной сорта Надежда с целью совершенствования технологии возделывания. Результаты эксперимента показывают, что наибольшая урожайность стеблей (7,96-11,11 и 6,578,73 т/га) получена в наиболее благоприятные годы по метеоусловиям - 2017 и 2019 гг., наименьшая - в 2020 году (3,02-4,2 т/га). Предпосевная обработка удобрением Изагри Форс повышает урожайность семян на $11,1-14,1 \%$, протравителем ТМТД, ВСК - на 3,5-5,6\%. Наиболее отзывчивы растения конопли на взаимодействие протравителя, удобрения и внекорневой подкормки растений по вегетации, прибавка урожайности составила 0,37 т/га.

\section{Influence of technological techniques on the productivity of hemp in the conditions of the forest-steppe of the Middle Volga region}

\begin{abstract}
The results of the research work of 2017-2020 on the influence of presowing seed treatment and non-root fertilization of plants on increasing the yield and quality of hemp products of the Nadezhda variety in order to improve the cultivation technology are presented. The results of the experiment show that the highest yield of stems (7.96-11.11 and 6.57-8.73 t/ha) was obtained in the most favorable years for weather conditions in 2017 and 2019, and the lowest - in 2020 (3.02-4.2 t/ha). Pre-treatment fertilizer Isagri Force increases the seed yield by $11.1-14.1 \%$, and the fungicide TMTD, VSK - by $3,5-5,6 \%$. The most responsive cannabis plants were to the interaction of the mordant, fertilizer and foliar top dressing of plants during the growing season, the increase in yield was $0.37 \mathrm{t} / \mathrm{ha}$.
\end{abstract}




\section{Введение}

Конопля посевная (Cannabis sativa L.) - очень ценная техническая культура, имеющая большое народнохозяйственное значение. Возделывают ее для получения волокна и на семена [1]. Урожайность любой сельскохозяйственной культуры определяется рядом факторов. Во-первых, определяющую роль играет сорт - его потенциальная, заложенная генетически продуктивность. Во-вторых, условия возделывания, позволяющие максимально реализовать потенциальные возможности сорта $[2,3]$. Не менее важную роль в повышении урожайности и улучшении качественных показателей играют средства защиты семян, которые позволяют управлять процессом роста и развития растений, что позволяет в полной мере реализовать потенциал культуры $[4,5]$ Применение внекорневой обработки растений в комплексе с аминокислотами и микроэлементами максимально повышает эффективность их действия. Кроме того, листовая подкормка позволяет осуществить быструю и точную доставку элемента именно в критический период развития.

Установлено, что применение предпосевной обработки семян перед посевом снижает уровень инфекции на 19-51\%. Однако проведение только такого мероприятия является недостаточным, поэтому дополнительно необходимо опрыскивание вегетирующих растений [6-11]. Известно, что такое опрыскивание растений снижает поражаемость культуры болезнями, позволяет бороться с негативным влиянием стрессовых факторов на растение - засухой, заморозками, гербицидным угнетением, способствует улучшению качества получаемой продукции, а также повышает урожайность.

\section{Методика}

Для комплексного изучения элементов технологии возделывания конопли посевной сорта Надежда работу выполняли в 2017-2020 гг. в полевом опыте с последовательным расположением делянок. Посев семян проводили по чистому пару. Трехфакторный опыт включал следующие варианты: фактор А предпосевная обработка протрави телем: контроль (обработка водой); ТМТД, ВСК (5 л/т); ТМТД, ВСК $(2,5$ л/т); фактор В - предпосевная обработка удобрением: контроль; Изагри Форс (1,0 л/т); Изагри Форс (0,5 л/т); фактор С - внекорневая подкормка растений удобрением: без обработки; обработка растений в фазе 5-6 листьев удобрением Изагри Фосфор в норме расхода препарата 3 л/га. Способ посева широкорядный с шириной междурядий 45 см, норма высева - 0,8 млн всхожих семян на гектар. Посев сеялкой $\mathrm{CH}-16$ проводили 3 мая (2017 г.), 4 мая (2018 г.), 1 мая (2019 г.) и 6 мая (2020 г.). Для агрохимического анализа проводили отбор почвенных образцов на глубину пахотного горизонта (0-30 см). Почва опытного участка - чернозем выщелоченный, среднемощный, тяжелосуглинистый с содержанием гумуса 6,18-8,00\% (по Тюрину). Почва обеспечена содержанием гидролизуемого азота 9,089,44 мг/100 г, подвижного фосфора - 19,72 мг/100 г почвы (по Чирикову), $\mathrm{S}_{\text {осн. }}-31,72$ мг-экв. на 100 г почвы.

За все время проведения эксперимента температурный режим и количество осадков за вегетацию было неодинаковым. Средняя за четыре года сумма активных температур за этот период составляла $2048,3^{\circ} \mathrm{C}$, что на $1,3{ }^{\circ} \mathrm{C}$ ниже среднемноголетнего значения (таблица 1). Количество осадков за период май - август резко различалось по годам исследований. В среднем за годы эксперимента количество осадков составило 136,1 мм (67,5\% от среднемноголетнего значения). В 2018 г. выпало 65,5 мм (32,5\% нормы), в 2020 г. - 203,9 мм (101,1\% нормы). Сезоны 2017 и 2019 гг. не имели настолько резких отличий по этому показателю и находились на уровне 136,7-138,3 мм, что ниже среднемноголетнего значения на 31,5-32,2\%.

По значению ГТК условия 2018 г. характеризовались как сильная засуха (ГТК = 0,32), в 2017 и 2019 гг. влагообеспеченность была недостаточной (ГТК $=0,67-0,68$ ), в 2020 г. - удовлетворительной (ГТК = 0,99). Самыми благоприятными для вегетации конопли оказались метеорологические условия 2017 и 2019 гг. Неблагоприятным по условиям увлажнения был 2018 г. Вследствие больших различий в метеорологических условиях урожай конопли по годам резко колебался.

\section{Результаты}

Результаты эксперимента показывают, что наибольшая урожайность стеблей $(7,96-11,11$ и 6,57-8,73 т/га)

Таблица 1. Характеристика метеорологических условий периодов вегетации 2017-2020 гг.

Table 1. Characteristics of meteorological conditions of the 2017-2020 vegetation periods

\begin{tabular}{|c|c|c|c|c|c|c|}
\hline Показатель & 2017 r. & 2018 r. & 2019 r. & 2020 r. & Среднее & $\begin{array}{c}\text { Среднемно- } \\
\text { голетнее } \\
\text { значение }\end{array}$ \\
\hline $\begin{array}{l}\text { Сумма активных тем- } \\
\text { ператур, }{ }^{\circ} \mathrm{C}\end{array}$ & 2021,8 & 2051,0 & 2042,0 & 2078,0 & 2048,3 & 2075,0 \\
\hline $\begin{array}{l}\text { Количество осадков, } \\
\text { мм }\end{array}$ & 138,3 & 65,5 & 136,7 & 203,9 & 136,1 & 201,7 \\
\hline $\begin{array}{l}\text { Гидротермический } \\
\text { коэФФициент }\end{array}$ & 0,68 & 0,32 & 0,67 & 0,99 & 0,66 & 0,97 \\
\hline
\end{tabular}

Рис. 1. Урожайность стеблей в зависимости от изучаемых факторов, 2017-2020 гг.

Fig. 1. Yield of stems depending on the studied factors, 2017-2020

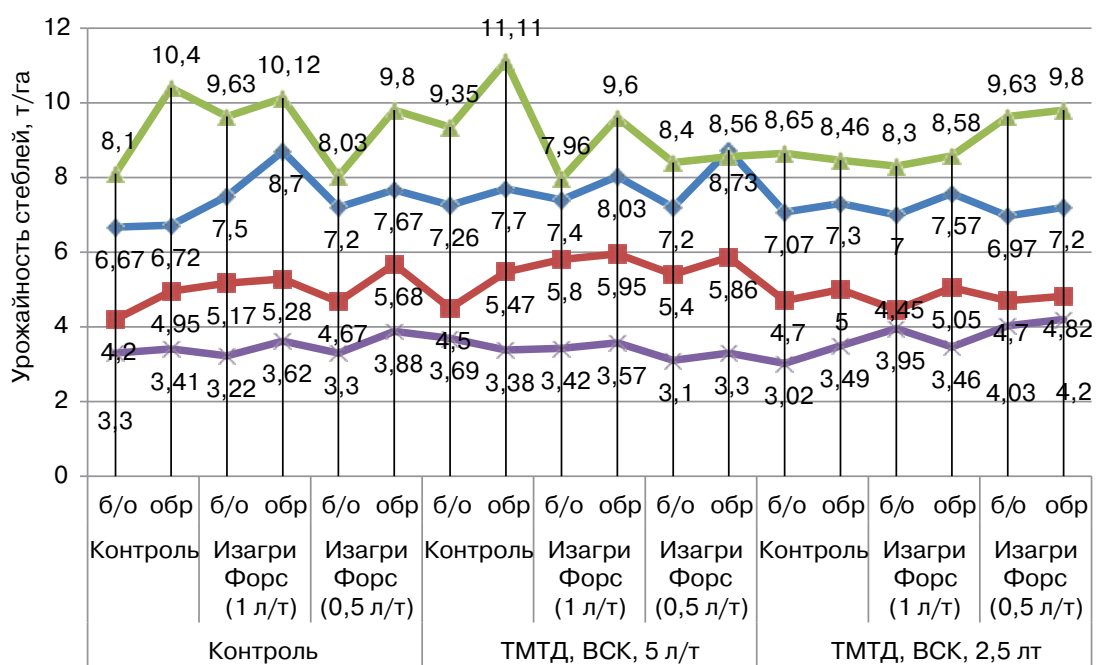

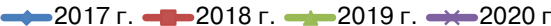


Pис. 2. Урожайность семян в зависимости от изучаемых факторов, 2017-2020 гг.

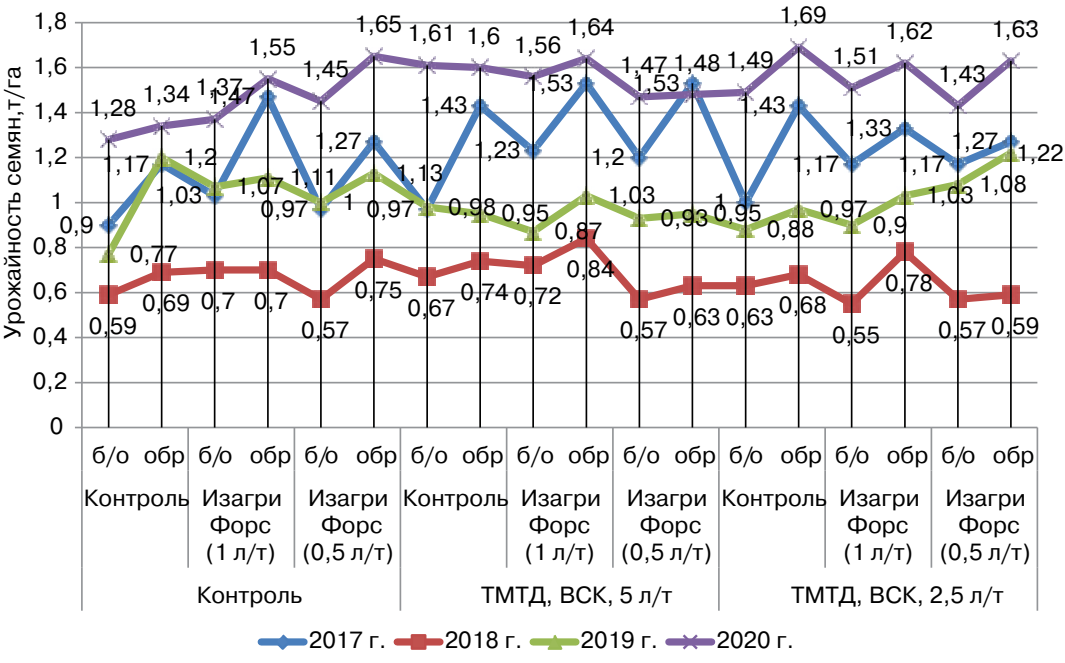
Fig. 2. Seed yield depending on the factors studied, 2017-2020

локна изменялся от 7,7 до 12,2\% $(\mathrm{Cv}=11,3)$. Содержание волокна увеличивалось на вариантах с обработкой Изагри Форс в норме расхода 1 и 0,5 л/т и ТМТД, ВСК в норме расхода 5 и 2,5 л/т и при взаимодействии изучаемых факторов. В условиях недостаточного увлажнения 2018 года выход общего волокна снижался до 22,2-28,7\% (Cv = 8,14), а длинного волокна - до 8,2-12,1 $(\mathrm{Cv}=10,1)$ соответственно. Применение внекорневой подкормки растений увеличило выход общего волокна на 2,2\% относительно контроля. По содержанию длинного волокна выделились варианты с предпосевной обработкой удобрением Изагри Форс, прибавка составила 3\% (при норме расхода 1 л/т) и $12,8 \%$ (при норме расхода 0,5 л/т). Применение внекорневой подкор-

получена в наиболее благоприятные годы по метеоусловиям - 2017 и 2019 гг., наименьшая - в 2020 году (3,02-4,2 т/га). Исходя из данных рисунка 1 видно, что для культуры характерно наибольшее изменение урожайности стеблей в зависимости от условий вегетации. Варьирование урожайности стеблей по вариантам опыта находилось в пределах от 7,67\% до 10,2\%, что говорит о слабой изменчивости признака в зависимости от изучаемых факторов. В среднем за годы исследований наибольшая прибавка урожая стеблей (9\%) получена от применения внекорневой подкормки, немного меньшая - от предпосевной обработки семян удобрением и протравителем $(2,4-3,7 \%)$.

По семенной продуктивности наблюдается явно выраженная тенденция повышения урожайности от применения внекорневой подкормки (прибавка 10,623,6\%). Этот факт говорит о том, что жидкое удобрение Изагри Фосфор оказывает положительное действие на образование и увеличение урожая семян конопли. Предпосевная обработка семян протравителем ТМТД, ВСК в повышенной норме расхода (5 л/т) способствовала увеличению урожайности семян на $12 \%$ в сравнении с контролем. Самую высокую урожайность семян получили при применении ТМТД, ВСК и Изагри Форс в полных нормах расхода (5,0 и 1,0 л/т) на фоне внекорневой подкормки 1,26 т/га, прибавка к контролю - 0,37 т/га (41,6\%). Не уступали по урожайности семян и варианты с применением препаратов ТМТД, ВСК в половинной норме расхода (2,5 л/т) и Изагри Форс в изучаемых нормах расхода (1,0 и 0,5 л/т) на фоне внекорневой подкормки. При этом урожайность повышалась на 0,30 и 0,29 т/га (33,7 и 32,6\%) соответственно по сравнению с контролем без обработок (рисунок 2).

Конопля в основном возделывается для получения волокна и семян [12]. Высокое содержание волокна в тресте конопли было в 2017 году: общий выход варьировал от 23,5 до $31,8 \%(\mathrm{Cv}=8,1)$, выход длинного во-

\section{ЛИТЕРАТУРА.}

1. Серков В. А. Формирование сортового разнообразия и совершенствование приемов технологии выращивания семян безнаркотической однодомной конопли в Среднем Поволжье. Автореф. диссер. на соискание уч. ст. доктора мки растений увеличило содержание длинного волокна на 5\% относительно контроля. В среднем, признак «разрывная нагрузка волокна» изменялся в пределах от 15,6 кгс (низкая) до 21,4 кгс (средняя) и имел наибольшие параметры на вариантах протравливания ТМТД, ВСК. Применение удобрения Изагри Форс в норме расхода препарата 1 л/т увеличивало данный показатель на $10,4 \%$, внекорневая подкормка повышала разрывную нагрузку волокна на $6,8 \%$.

Экономически наиболее эффективным приемом при возделывании культуры является посев обработанными протравителем ТМТД, ВСК семенами в нормах расхода 5,0 и 2,5 л/т с удобрением Изагри Форс в норме расхода 1,0 л/т на фоне внекорневой подкормки удобрением Изагри Фосфор. При этом чистый доход составлял 161 и 151 тыс. руб./га, рентабельность - 245,7 и 237,6\% соответственно.

\section{Выводы}

Применение предпосевной и внекорневой обработок на конопле посевной является фактором повышения урожайности и качества коноплепродукции. Максимальная урожайность получена в варианте обработки семян ТМТД, ВСК и Изагри Форс в полных нормах расхода (5,0 и 1,0 л/т) на фоне внекорневой подкормки (3 л/ га) - прибавка к контролю 0,37 т/га (41,6\%). По показателям экономической эффективности наилучшим оказался вариант опыта с обработкой семян смесью препаратов ТМТД, ВСК в нормах расхода 5,0 и 2,5 л/т с удобрением Изагри Форс в норме расхода 1,0 л/т на фоне внекорневой подкормки удобрением Изагри Фосфор. При этом чистый доход составлял 161 и 151 тыс. руб./га, рентабельность - 245,7 и 237,6\% соответственно. Таким образом, для повышения урожайности и качества продукции необходимо проводить предпосевную обработку семян конопли посевной, а также внекорневое опрыскивание по вегетирующим растениям. 
ментов технологии возделывания на продуктивность нового сорта рапса озимого Самрат. Вестник АПК Ставрополья. 2020. № 4 (40). C. 56-61. [Agafonov O. M., Revenko V. Yu. The influence of certain elements of cultivation technology on the productivity of a new variety of winter rape Sa-mrat. Bulletin of the Agroindustrial Complex of Stavropol. 2020. No. 4 (40). pp. 56-61.].

3. Гладков Д.В., Плотников А.М., Субботин И.А. Продуктивность конопли посевной в зависимости от норм высева и применения средств химизации. Вестник Курганской ГСХА. 2018. № 1 (25). C. 18-20. [Gladkov D. V., Plotnikov A.M., Subbotin I. A. Productivity of hemp seed depending on the seeding rates and the use of chemical agents. Bulletin of the Kurgan State Agricultural Academy. 2018. No. 1 (25). pp. 18-20.].

4. Минеев, В. Г. Удобрение и качество продукции. М.: Знание. 1980. 64 с. [Mineev, V. G. Fertilizer and product quality. Moscow: Znanie. 1980. 64 p.].

5. Шамова М. Г., Уткина Е.И., Кедрова Л.И. Влияние крупности ис-ходного семенного материала на формирование урожая и семенные качества озимой ржи. Методы и технологии в селекции растений: Матер. Всерос. науч.- практ. конф. с международным участием. Киров. 2014. С. 202-206.[Shamova M. G., Utkina E. I., Kedrova L. I. Influence of the size of the original seed material on the formation of the crop and seed quality of winter rye. Methods and technologies in plant breeding: Mater. Vsros. nauch.- practical conference with international participation. Kirov. 2014. P. 202-206.]

6. Анспок П.И. Микроудобрения: Справочник. СПб.: Агропромиздат. 1990. 272 с. [Anspach P. I. Micronutrient: A Handbook. SPb.: Agropromizdat. 1990. 272 p.]

7. Привалов Ф.И., Цыганов А.Р. Микроудобрения в составе защитно-стимулирующих смесей. Достижения науки и техники АПК. 2009. № 5. С. 31-33. [Privalov F. I., Tsyganov A.
R. Microfertilizers in the composition of protective-stimulating mixtures. Achievements of science and technology of the Agroindustrial Complex. 2009. No. 5. pp. 31-33.].

8. Серков В.А., Смирнов А.А., Бакулова И.В., Плужникова И.И., Криушин Н.В, Климова Л.В. Возделывание однодомной конопли посевной среднерусского экотипа. Практические рекомендации. Пенза: ФГБОУ ВО Пензенский ГАУ. 2018. 37 с.[ Serkov V. A., Smirnov A. A., Bakulova I. V., Pluzhnikova I. I., Kriushin N. V., Klimova L. V. Cultivation of monoecious hemp of the Central Russian ecotype. Practical recommendations. Penza: FGBOU VO Penza State University. 2018. 37 p.].

9. Торопова Е.Ю., Стецов Г.Я. Предпосевное протравливание семян (методические аспекты). Защита и карантин растений. 2018. № 2. С. 3-7. [Toropova E. Yu., Stetsov G. Ya. Presowing seed treatment (methodological aspects). Plant protection and quarantine. 2018. No. 2. P. 3-7].

10. Цыганов А.Р., Персикова Т.Ф., Реуцкая С.Ф. Микроэлементы и микроудобрения: учебное пособие. Минск: РуП «Издательский дом «Белорусская наука». 1998. 122 с. [Tsyganov A. R., Persikova T. F., Reutskaya S. F. Microelements and microfertilizers: a textbook. Minsk: Republican unitary enterprise "Publishing house "Belarusian science". 1998. 122 p.].

11. Чулкина В.А., Торопова Е.Ю., Стецов Г.Я. Интегрированная защита растений: фитосанитарные системы и технологии. М.: Колос. 2009. 670 с. [Chulkina V. A., Toropova E. Yu., Stetsov G. Ya. Integrated plant protection: phytosanitary systems and technologies. 2009. $670 \mathrm{~s}$.].

12. Жатов А. И. Методы получения исходного материала для селекция конопли. Автореф. дис. доктора с-х наук. Ленинград, 1974.- 58 с. [Zhatov A. I. Methods of obtaining the source material for the selection of hemp. Autoref. dis. Doctor of agricultural sciences. Leningrad, 1974. - 58 p.]

\section{НОВОСТИ•НОВОСТИ•НОВОСТИ•НОВОСТИ॰}

\section{В Башкирии строится завод по производству масла из конопли}

В Кушнаренковском районе Республики Башкортостан ООО «Башхемп-агро» занимается строительством завода по производству конопляного масла, семян и другой экологически чистой продукции (всего 50 наименований) из безнаркотической конопли. Как сообщил в рамках «Инвестчаса» заместитель гендиректора компании Эдуард Рамазанов, общий объем вложений в данный проект составит 200,5 млн руб., при этом будет создано 75 новых рабочих мест. Ввод в эксплуатацию единственного в республике предприятия по переработке и производству продукции из технической конопли запланирован на 2022 год.

Основная цель создателей данного проекта - восстановление и развитие в республике отрасли коноплеводства, создание новых рабочих мест, обеспечение внутреннего и внешнего рынка продуктами питания и неткаными полотнами различного назначения.

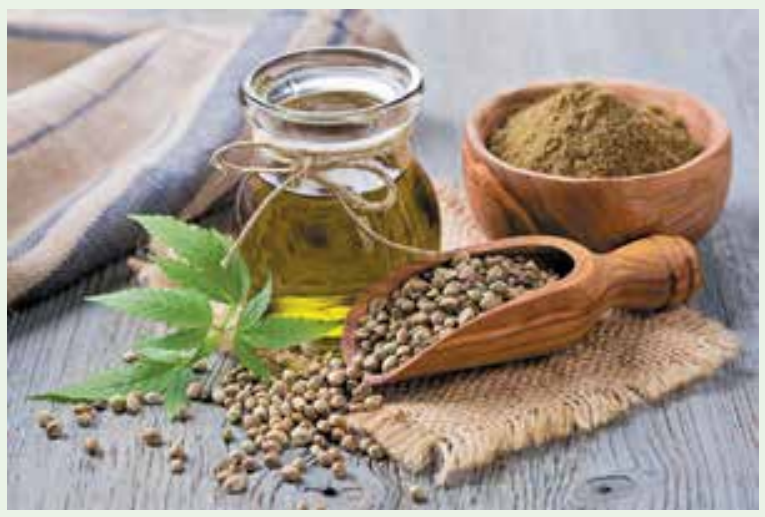

\section{Президент России подписал закон о повышении штрафов за непринятие мер по уничтожению конопли}

\footnotetext{
В.В. Путин подписал закон об увеличении штрафов за несвоевременное уничтожение и культивирование дикорастущих наркотических растений, таких как конопля. Документ (Федеральный закон от 05.04.2021 № 84-Ф3 «О внесении изменений в Кодекс Российской Федерации об административных правонарушениях») опубликован на официальном портале правовой информации. Изменения вносятся в статью 10.5 Кодекса РФ об административных правонарушениях (КоАП), которая предусматривает ответственность за непринятие землевладельцем или землепользователем, после получения официального предписания, мер по уничтожению дикорастущих растений, содержащих наркотические средства, психотропные вещества либо их прекурсоры. Штрафы для граждан повышаются с 1,5-2 тыс. руб. до 3-4 тыс. руб., для должностных лиц - с 3-4 тыс. руб. до 5-10 тыс. руб., для юридических лиц - с 30-40 тыс. руб. до 50-100 тыс. руб.

Помимо этого поправки вносятся в статью КоАП о непринятии должностным лицом мер по обеспечению охраны посевов и мест хранения таких растений, мер по уничтожению пожнивных остатков и отходов производства, в составе которых есть наркотики. Закон повышает штрафы за данное правонарушение, устанавливая их в размере от 5 тыс. руб. до 10 тыс. руб. Незаконное культивирование растений, содержащих наркотические средства, психотропные вещества либо их прекурсоры, без признаков уголовно наказуемого деяния теперь влечет за собой штраф от 3 тыс. руб. до 5 тыс. руб. или административный арест на срок до 15 суток.
} 